\title{
Chapter 14 \\ Theoretical Aspects of Doing Research in Mathematics Education: An Argument for Coherence
}

\author{
Stephen Lerman
}

\begin{abstract}
One of the hardest tasks for new researchers, actually all researchers throughout their careers, is what theory to use to inform their work, and how to work with theory. In this chapter I try to set out what theory is for, in research, and what are the challenges for theory choices. I indicate that we are in a period of proliferation of theories, one from which there is no going back, if indeed there was ever a time without such choices being faced. I look on this proliferation as positive for our work, not a hindrance to progress, as some in our field believe. I am not aiming for an encyclopaedic approach, a full list of all theories and how they might inform research. Were I to attempt such a task new theories would have emerged before the chapter appears in print. I try to explain how that happens, in this chapter. Instead I take a position in relation to theory, a position that informs the writing of the whole chapter; I look for coherence of theoretical work, as it informs research.
\end{abstract}

Keywords Theory · Research • Proliferation • Coherence

\subsection{Introduction}

In this chapter I focus on recruitment of, and working with, theories in mathematics education research in a time of proliferation of theories. The task of reading about theoretical perspectives on learning, on teaching, on community, on communication, on mathematics, and so on is a demanding one. The growth of theories over the recent decades makes the task much more difficult. I will discuss why this proliferation exists and suggest it might be a good thing, though there are many people in the field who do not agree.

The task for research students is to make some choices regarding these theories, and which theory or theories will be the ones to be worked with in their research. Some will argue that the research questions drive that choice, and it does not matter

\footnotetext{
S. Lerman $(\bowtie)$

London South Bank University, London, UK

e-mail: lermans@1sbu.ac.uk

(C) The Author(s) 2019

G. Kaiser and N. Presmeg (eds.), Compendium for Early Career

Researchers in Mathematics Education, ICME-13 Monographs,

https://doi.org/10.1007/978-3-030-15636-7_14
} 
which theories are taken up as long as they can provide answers to the research questions. Still others will argue for the recruitment of a range of theories, each of which will offer a different perspective or outcome of the research and all of which are valid. I will present some thoughts on these and other challenges in recruiting and working with theory.

This chapter is not, however, an encyclopedia of research theories, nor of research methods. I take a position in relation to theories and that is one of seeking coherence. There are many good textbooks that provide information across the educational field (e.g., Cohen et al. 2018). There is also the Encyclopedia of Mathematics Education for specifically mathematics educational material, including very detailed information on theories (Lerman 2014a).

A successful research study at doctoral level can be achieved by working with one established theory and drawing on the body of work that appears in the literature for operationalization of that theory, for identification of research questions, for appropriate research methods and for analysis of data. Coherence across these four central elements of research and of writing a thesis is essential. A good doctoral study can be achieved by recruiting more than one theory but again I will argue for coherence. Some theories contradict others. If you are going to use more than one they should work together and you will need to do some work to show that they do, and how they do. I will discuss and exemplify these points too.

I like to think that research in mathematics education develops our thinking as a community and pushes forward our understanding of the processes of teaching and learning mathematics. I like to hope that we have good effects on practice in teaching and learning mathematics too. I have to admit, however, that it is not easy to see how one can judge progress in any way that convinces, even in one sociocultural context, let alone more widely. I will leave that sceptical concern aside though, for the purposes of this chapter. Those discussions are for elsewhere.

\subsection{Theory Proliferation}

Education, as one of the social sciences, is a special kind of field, what Bernstein, the sociologist of education, called a 'region' (see, e.g., Bernstein 2000). Unlike, say, the field of psychology, or the field of science, it draws both on theory and on practice. It is similar to medicine in that sense. In mathematics education we have a face towards intellectual fields such as psychology, anthropology, philosophy, sociology, semiotics and so on. Each and all of these fields have something to say to education, something we can draw from in thinking about and researching teaching and learning. In addition, we have another face, towards practice. Research questions generally arise from practice and should, ultimately, have something to say to and about practice.

A further important and significant feature of educational research is that, according to Bernstein, it exhibits a 'horizontal knowledge structure'. Science, in contrast, exhibits a 'vertical knowledge structure', because, as theories and 
knowledge grow, they replace previous theories and knowledge. Phlogiston theory was replaced by the discovery of oxygen; the notion of the earth as the centre of the universe was replaced by the sun as the centre of our immediate universe; the theory of relativity replaced Newtonian mechanics, and so on. Of course this is somewhat simplified. Sometimes theories are subsumed into newer ones; competing theories can remain for a long time until technology reaches a stage where suitable critical experiments can be carried out to resolve which is deemed correct. The history and philosophy of science is full of such events and disputes. Kuhn (1978) argues that old 'normals' are replaced by the new 'normals', but proceed in this way through conflicts, initially at the periphery, but eventually at the centre.

However, Bernstein is arguing that the new 'normal' today, at the meta-level, which Kuhn presents as a linear process of theory development, is on the contrary proliferation, a multiplicity of perspectives and languages. Horizontal knowledge structures, according to Bernstein, develop in two ways: with the creation of new theories or languages/discourses; and within existing theories or languages/ discourses. This is typical of the social sciences, but also, strangely, of mathematics itself, though another important distinction, which will not be developed here, is that of the strength of a grammar; that is to say, how precise in meaning are the terms used. Mathematics has a strong grammar; the difference between a ring and a field are very precise, for example. Social science, and education in particular, has a very weak grammar. If we were to discuss what 'understanding' means and how we identify it in learning we might talk for days without reaching consensus. New fields, or better, sub-fields of mathematics develop, string theory for example, but do not replace other sub-fields. As the sub-field develops the language (theorems etc.) becomes so specific that mathematicians in other sub-fields can hardly understand each other.

In mathematics education, as new theories develop, they sit alongside existing ones. We might have expected that behaviourism, a psychological theory that dominated educational thinking until the early part of the 20th century would, perhaps, have been replaced in education, either by Piagetian or by Vygotskian theories, as both thinkers were opposed to behaviourism, considering it to be a theory very limited in its relevance to human cognitive development at least, but that did not happen. Behaviourism still has its proponents and is still researched. It appears in classrooms as behaviour modification techniques (gold stars for good behaviour for example), and in therapy for the treatment of specific phobias, such as fear of spiders.

Vygotsky's writings became known in education outside of the Soviet Union only in the 1960s and 1970s. Vygotsky was critical, in quite fundamental ways, of Piaget's ideas but, once again, these two theories sit alongside each other, giving competing accounts, stories, of how children learn and what is the role of teaching. Neither replaces the other. I shall have more to say about Piaget and Vygotsky later in this chapter. A quite recent development has been the introduction of biosocial theories (de Freitas 2017), offering new perspectives on learners and learning.

This account of knowledge structures and theory development by Bernstein is at least one way of accounting for the proliferation of theories. As well as 
behaviourism, Piagetian and Vygotskian/sociocultural theories, in mathematics education research we can point to enactivism, socio-political theories, critical theory, post-structuralism and postmodernism, and work informed by Levinas, Kant, and Aristotle. This list is by no means exhaustive. Karmiloff-Smith and Inhelder (1974) wrote a paper entitled 'If you want to get ahead get a theory' to capture the phenomenon of research students, or more experienced researchers, thinking that if they can find a theory new to the field they may be assured of success in their thesis and career. In fact it is usually the case that new theories do provide new insights and new ideas for researching the teaching and learning of mathematics and its wider context. It is certainly not just a strategy for carving out a career path.

Historically, in terms of the mathematics education research community, psychology was the main knowledge domain on which researchers drew. Hence the name of the leading research group, the International Group for the Psychology of Mathematics Education, known as PME. It was founded in 1976 and has met annually ever since. In 2005 the constitution was changed to give equal credit to research drawing on other perspectives, though I think it fair to say that psychology remains the leading theoretical field. The proliferation of theories has been matched by an increasing range of journals and conferences on mathematics education, supporting the opportunity for new ideas and theories. The series of conferences called Mathematics, Education and Society (MES) that began in Nottingham in 1998 and will hold its 10th meeting in 2019, focuses on political, sociological and other perspectives, and was established to enable researchers who were not working with psychological theories to have a forum for writing, meeting and networking. As I write this chapter, the 6th International Conference on Ethnomathematics is being held in Colombia. These are just some of the examples.

I have not yet mentioned Mathematics as one of the theoretical fields that impact significantly on our research. It is obvious of course. Mathematics education research is essentially about mathematics just as art education research is about art. But we cannot just say 'mathematics' without thinking about the range of ways we need to think about it and what part that plays in our research. Mathematics is about problem-solving; mathematics is a body of certain knowledge; mathematical thinking is a way of seeing the world, a lens through which to see circles in wheels etc.; mathematics is a powerful tool in formatting society, including its inequalities; traditional mathematics teaching does violence to children; inquiry/reform mathematics is the panacea; children from disadvantaged backgrounds do no better in reform mathematics classrooms than in traditional ones. These are just some of the competing views that surround our research in relation to mathematics and about which researchers often have to take a position. It is quite legitimate of course to choose to work with the status quo, the existing mathematics curriculum, if the research is in schools or Universities, without feeling required to take a position on what mathematics is. Studies of workplace or street mathematics will engage directly and necessarily with what mathematics is, or perhaps better expressed as what it is for. Research on what might be the best environment for students to learn 
mathematics, and that includes pre-service or in-service teachers, will need to take into account the range of ways that the subject can be perceived.

We should not leave the way we perceive the field of mathematics as it might/ should impact on mathematics education research without referring to Hans Freudenthal's most important work. His 'psychology' of mathematics learning, and he was one of the founders of PME, he called didactical phenomenology. He saw learning as a tour of discovery and teaching as guiding that discovery. He argued that students learn mathematics best by reinventing it, recognising that the discoveries of school students would be new to them but not to the world of mathematics. He argued that all students taught in the way he described ought to be able to succeed in learning mathematics.

I see our task as a research sub-field to seek an explanation of how socially, culturally and historically located knowledge, in our case knowledge of mathematics, becomes the knowledge of the individual in that society at that time. An equally important question is why, for so many children from disadvantaged backgrounds, in many countries around the world, that knowledge does not become theirs; they are excluded. The nature of the knowledge, whether of science, history or art, must play a significant role in conceptualising teaching and learning and therefore research. Mathematics presents unique challenges of course. Consider some of the features of mathematics: proof and proving; certainty of results, abstract objects to be handled and manipulated; success in the subject highly valued across the world, taken as an indicator of intellectual ability more generally; a climate of bewilderment for most people, including parents of children studying the subject; the list can go on. The teacher of mathematics, similar but also different to teachers of other subjects, most similar to science teachers, together with textbooks where they are used, is the arbiter of what is correct and what is not. In a class discussion of even and odd numbers a child might claim that one is even because it can be split into two halves. We might all agree that the proposal is delightful and creative, but outside the definition of even and odd. Somehow the teacher has to correct the knowledge whilst retaining the climate of supporting children's thinking and imagination. A much deeper analysis of this kind of challenge and dilemma for teachers can be found in the extensive work of Deborah Ball and her colleagues (see, e.g., Ball 1993).

\subsection{Incommensurability and 'Home-Grown' Theories}

There have been, and continue to be, some in our community who consider this proliferation to be damaging as we find it increasingly hard to speak to each other across languages/discourses, an incommensurability of meanings, and this limits the work we can do, but especially the chance that our work might affect positively what goes on in school mathematics (e.g., Goldin 2003). First, this proliferation is typical in thought in the 21st century: it should not be surprising therefore that we see the same in mathematics education research. Since the 'Pandora's box' has been 
opened, in this sense, how can it be closed again? Which theory would be the one agreed and accepted by everyone? We could even ask which intellectual field, psychology, sociology, political theory for example, would provide the best research context? I think that sociology, with its ability to explain the appearance of multiple theories and their relationship to each other, has been a vital feature in mathematics education research since it entered the field in the 1990s. But I am not alone in arguing that we gain enormously from the research in mathematics education just because of the range of theories and we would lose far more than we might gain by attempting to narrow that range. Lather (2006), for example, argues that the call for simplification aligns with the neo-positivist response, called by Hodkinson (2004) the 'new orthodoxy', to anxieties raised by postmodernism. Lather says:

Against this new orthodoxy, I have endorsed a 'disjunctive affirmation' of multiple ways of going about educational research in terms of finding our way into a less comfortable social science full of stuck places and difficult philosophical issues of truth, interpretation and responsibility. Neither reconciliation nor paradigm war, this is about thinking difference differently, a reappropriation of contradictory available scripts to create alternative practices of research as a site of being and becoming. (p. 52)

Just as the well known visual version of incommensurability below (Fig. 14.1) means you can see only one image at a time, the faces or the vase, but you can see both successively, so too I can 'speak' both the languages of sociocultural theory and radical constructivism, which are argued to be incommensurable (Lerman 1996).

The issue for researchers in mathematics education is how competing theories are chosen, worked with, and why, in the search for justifiable answers to research questions. Theories, as discourses, offer worldviews. They are much more than a framing for research methods. As I will discuss below, working with worldviews that differ in fundamental ways can lead to incoherence, an attempt to see both the vase and the faces at the same time. An argument can be made for layers of interpretations of research findings, each layer drawn from a different theoretical

Fig. 14.1 Face vase optical illusion

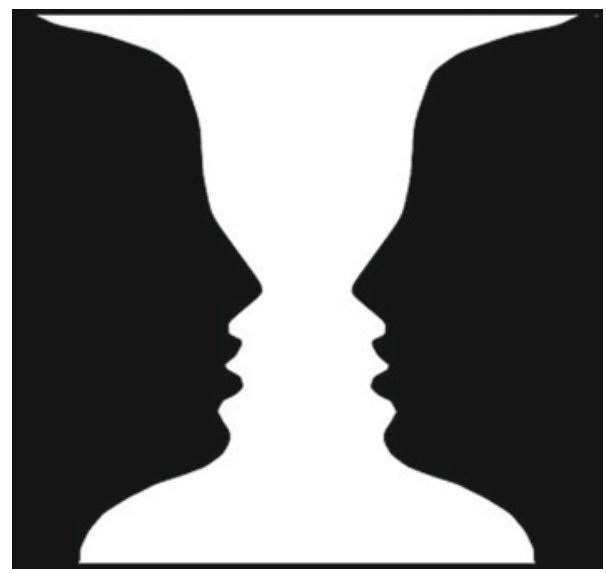


framework. Nevertheless, researchers working with opposing theories will need to work very hard to make sense of their analysis to avoid a kind of stalemate of opposing accounts that cannot be brought together usefully.

There have also been some who regret that all our theories have been drawn from outside mathematics education research and we lack 'home-grown' theories (Kilpatrick 1981). Silver and Herbst (2007) claimed that this has long been the goal of some pioneers in our field such as H. G. Steiner, though their approach is along the lines of the new orthodoxy critiqued by Lather. They write:

The development of a grand theory of mathematics education could be useful in providing warrants for our field's identity and intellectual autonomy within apparently broader fields such as education, psychology, or mathematics. In that sense, a grand theory could be helpful to organize the field, imposing something like a grand translational or relational scheme that allows a large number of people to see phenomena and constructs in places where others only see people, words, and things. A grand theory of the field of mathematics education could seek to spell out what is singular (if anything) of mathematics education as an institutional field or perhaps seek to spell out connections with other fields that may not be so immediately related and that establish the field as one among many contributors to an academic discipline. (p. 60)

In contrast, Sriraman and English (2010) argue the following:

We however do not agree with the claims of Silver and Herbst for the following reason. In Sriraman and English (2005) we put forth an argument on the difficulty of abstracting universal invariants about what humans do in different mathematical contexts, which in turn, are embedded within different social and cultural settings; this suggests that it is a futile enterprise to formulate grand theories. At this point in time such a grand theory does not appear evident, and indeed, we question whether we should have such a theory. (p. 17)

Bernstein uses the term 'recontextualisation' to refer to the process of taking a discourse developed in one context and moving it to another. It is a process at the heart of education. For example, Piaget's psychological studies have been recontextualised as principles of learning. He was not an educator, though he followed closely how his work was reinterpreted and selected for school classrooms. Elements of research produced in the mathematics education research community are selected and recontextualised for teacher education courses and texts and for school classrooms. Bernstein (1990) wrote:

The recontextualising rules regulate not only selection, sequence, pace, and relations with other subjects, but also the theory of instruction from which the transmission rules are derived. (p. 185)

That selection is not a neutral process. Selection always takes place driven by principles at the more local level, and ideology at a macro-level. In many countries most people engaged in research in mathematics education are also teacher educators. The choice of what is presented as pedagogic principles are backed up by a selection from research. In turn, what gets selected by student teachers as they progress into schools is again a recontextualisation (Ensor 2001).

Similarly, researchers recontextualise theories when they are brought into our field, and in this sense they become 'home-grown'. That is an essential part of the 
process of working with theory. Laying out Hegelian principles of judgement in the literature review requires an elaboration by the researcher of how those principles, developed by Hegel in a certain cultural-historical context and for certain purposes, can be useful in mathematics education research; Hegel's ideas are recontextualised for new purposes in a new context (Davis 2001). Perhaps 'home-recontextualised' is a better characterisation than 'home-grown', if rather more clumsy.

\subsection{Working with Theoretical Frameworks, and Paradigms}

I want to elaborate a little further here what it might mean to 'use' a theory. To the best of my knowledge Bakhtin never wrote about educational research and for sure not about mathematics education research. Those who take up the ideas of Bakhtin for their research are in fact doing the work of seeing relevance in what he wrote about discourse, communication and meaning, for classrooms, or teaching or whatever. It is therefore more appropriate to think in terms of working with, harnessing, or, as I have written above, recruiting theoretical ideas from elsewhere to guide thinking about the research problem(s). That necessitates work to justify the selection of particular theories or ideas to help frame and interpret the research problem in ways that can then be researched. If I see my goal as researching why children from disadvantaged backgrounds in England do worse in mathematics than other children I would need to seek for a theory that can engage with the problem. I would argue (remember, this is not a neutral chapter; it is written from my position) that radical constructivism cannot help me. But sociologists of education such as Basil Bernstein, Michael Apple, and Pierre Bourdieu can, because they have theorised how and why the phenomenon of schooling reproducing disadvantage (and advantage) occurs. Now my job is to recruit key ideas from one of those sociologists for my particular study.

This is a most important stage in research and one that has to be done properly. By this I mean that the research student has to read deeply and widely in the work of their chosen theorist(s). It is no good cherry picking a few ideas from someone else's research in place of doing the reading and learning the language oneself. The 'gate-keepers' in the community (examiners, journal editors and reviewers, grant committees) will see through this strategy. The languages of these theorists are very specific; that's why they have something useful and powerful to offer. Whether it be Halliday's systemic functional analysis; Bernstein's pedagogic device and recontextualisation rules; Piaget's concepts of accommodation, assimilation and reflective abstraction; the Marxist notion of ascent from abstract to concrete; or Vygotsky's stages of conceptual development, to be able to recruit the ideas to help frame the research requires serious engagement and hard work.

So how does one go about 'choosing' a theory? I think two issues come to the fore here. One is recognising which field I am in when I think about the research 
problems I am posing. Dowling and Brown (2010) describe this stage in research well. They ask is this question best addressed within psychology, or sociology or anthropology or some other field? Once I recognise that, I can narrow down the authors that I need to read and hence the scope of the literature. They call this identifying the theoretical field. When one chooses the setting within which the research will be carried out, namely, textbooks; school classrooms; workplace training or whatever, that is called the empirical field, and research is about the conversation between the two.

The second issue is what I'd call a personal/philosophical one. Assuming I have done the work required to understand the language and ideas of theorists, I may find the ideas of one appealing to me more than another. This may be about finding inspiration in one author more than others, my own history of ideas, experiences and feelings, or particular sympathy for the author.

Having identified the research questions, almost always the starting point for research anyway, there is a temptation to choose a theory or theories according to what will work. Statistical testing of data is often thought to be a matter of applying a test and if it does not produce the result you want, try another test. Of course this does a disservice to statistics but my point is that 'what works' seems to assume a particular outcome and the researcher wants to make sure that he/she will find that result emerging from their study. A justification for theory choice, and also research methods on the basis of 'what works' doesn't work, at least for me. I am not referring to research methods here. I will say more below, but what methods I choose to gather data to help me find what will constitute answers to my research questions is a later process, and can be put under the heading of 'what works' in some sense. To return to my proposed research topic above, statistical techniques may well work for me in identifying factors that lead to the strong connection between social class and achievement. Or I might find that sitting in a range of classrooms observing how knowledge is distributed (another term from Bernstein's sociology of education) might work better. My criticism of justification of theory in terms of 'what works' is that it carries a whole set of intended principles and outcomes from the research that are not spelt out in advance.

In summary, we could say that our job is putting theories to work in research. As I have suggested above, this could be a single elaborated theory. The French term bricolage taken from the notion of building construction, encourages the idea of working with multiple theories and constructing a framework out of them that will then be worked upon in order to frame the research. Prediger et al. (2008, p. 8) suggest the idea of networking of theories, offering the following diagram (Fig. 14.2) to set out how that might work.

In my view one needs to worry about working with contradictory theories. Multiple theories are to be recommended, I feel, as long as there is coherence between them. Within my position on theories, I would say that working with sociocultural theory at a macro-level of a classroom of school students but then turning to constructivist theories to work at the individual level (see Lerman 2013) is to be entering into a clash of competing theories. I develop this position below. 


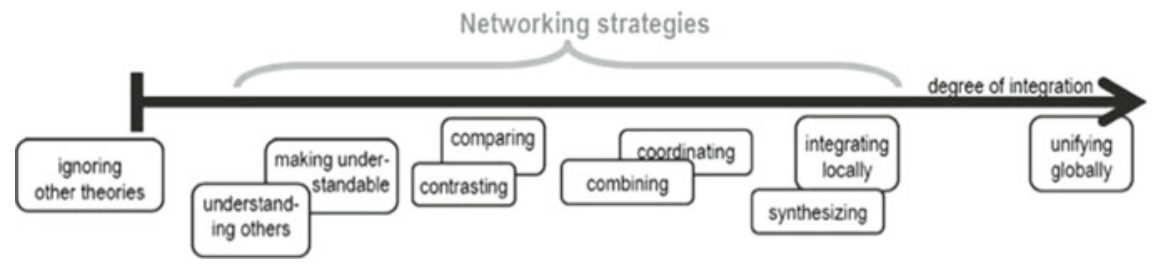

Fig. 14.2 A landscape of strategies for connecting theoretical approaches

\subsection{Methodology}

This chapter is not about methodology or methods. Other chapters will address these areas of research. I must, however, discuss the relationship between theories and methodology, as they are relevant to this chapter.

Let's be clear. Methodology is about the philosophy of research, strongly related to issues of truth. Where truth is to be found in social science research, and particularly in mathematics education research, our concern in this book, is the work of methodology. Is truth to be found in large numbers and statistical techniques of significance, such as in randomised tests? Is it to be found in deep studies of the life of classrooms? These are the kinds of questions to be considered and once again, like the choices faced in relation to theories, the choice of methodology is philosophical and to some degree personal/philosophical. A strong adherence to a scientific approach will pull one to the large-scale randomised studies and statistical techniques and positivism. It may be that a strong conviction that trying as far as is possible to enter into the life of the people and situations to be providing the data through ethnography, phenomenology, perhaps drawing on narrative methods, is required to answer the research questions.

Regarding the proliferation of theories, a phenomenon in education in general, not just in mathematics education research, Patti Lather (2006) has proposed a classification of methodologies in terms of paradigms, with a split coming with the appearance of post-structural and postmodern theories (Table 14.1).

I think this is very useful in that it makes clear the philosophical commitment of methodological choices.

Once again, 'methods' involve a different set of choices. A statistical analysis may well reveal important trends that would best be further investigated by ethnographic means. Statistical techniques may add a level of confirmation for connections that have appeared in ethnographic studies, or are suggested by theoretical orientations.

Table 14.1 Part of paradigm chart (Lather 2006, p. 37)

\begin{tabular}{l|l|l|l|l|l}
\hline Predict & Understand & Emancipate & Break & Deconstruct & Next? \\
\hline Positivist & Interpretive & Critical & & Poststructural & Neo-positivism \\
\hline
\end{tabular}




\subsubsection{A Coherent Framework for Research}

My goal to this point has been to set out the task of selection and working with theory or theories. I indicated that working with more than one theory requires the work of ensuring that there is coherence between those theories and how they will be recruited for research, though I made it clear that this is my view, and not held by all in the research community. Those working with or within complexity theory would completely disagree. Relevant sections of the Encyclopedia of Mathematics Education would lead readers to those ideas and research and researchers who work in that area.

In this section I look at what I see as a very common incoherence in research in our field, namely, a false distinction between cognition and social-cultural context. Put another way, constructivism, the individual construction of knowledge, or individual sense-making, provides the theoretical framing for studying cognition, whilst one must also take into account the social context, sometimes called sociocultural context. But the latter does not help with the former. It helps the researcher to discuss society and schooling within it but does not help with studying individual students' learning.

Researchers are attempting a blend of constructivism, derived from Piagetian theory, and sociocultural theory, devised by Vygotsky. At first glance that seems to make sense as a research programme. However, a deeper study of the work of these two great thinkers reveals that both were cognitive scientists, though firstly with a different understanding of the origins of cognition, and secondly that there are fundamental differences between the two sets of ideas. Vygotsky would be turning in his grave with the knowledge that some researchers in child development did not see that studying cognitive development through a cultural- historical lens was his whole life's work. His work too was cognitive science.

To take the first point, and I am focusing here specifically on the danger of incoherence in working with both theories of child development, both Piaget and Vygotsky were concerned with how children develop, addressing directly what I set out above as one of the two key tasks as a research sub-field, to account for how socially, culturally and historically located knowledge becomes the knowledge of the individual in that society at that time. They began their investigations of that task from two different directions. Piaget's background in biology led him to look to adaptation of the individual species. Children learn something new when a new experience causes a disequlibrium with existing knowledge, leading the child to assimilate that new knowledge into their existing mental make-up or accommodate to the new knowledge by a mental reorganisation. Vygotsky's background in philosophy and the arts, working at the time of the Russian revolution, and with his experience of the role of language in cognition, saw cognitive development as occurring as a result of immersion in a sociocultural setting. For Piaget, then, cognition comes about within the mind of the individual. For Vygotsky, meaning is first on the social plane, in the sociocultural context, and only subsequently on the individual plane. Researching learning from a Piagetian point of view starts and 
ends with the individual. Researching learning from a Vygotskian point of view starts with the social and then moves to the individual.

The second point, the fundamental differences between the theories, results from the first. For Piaget biological, mental development, maturation, leads learning. For Vygotsky learning leads to mental development. For Piaget language succeeds cognition and serves to organise it. For Vygotsky language precedes development, it pre-exists the individual and the individual internalises language and meaning. For Vygotsky, teaching and learning have to be taken together since one does not happen without the other. For Piaget, the teacher's actions are just one of the ways that the individual can experience disequilibrium. For Piaget learning begins in the concrete and moves to the abstract. For Vygotsky, learning involves the ascent from the abstract to the concrete.

My concern is to take these differences as an example of how one can slip into working with contradictory theories that can lead to incoherence. Bruner has addressed the same concern in a much more developed and eloquent way than I have here. In 1996, on the centenary of the birth of both Piaget and Vygotsky, at the Growing Mind conference, Bruner said the following in a keynote address:

\footnotetext{
So should we try to combine Piaget and Vygotsky into a common system in the hope of explaining both extremes of this astonishing human variability? I think that would be naïve. The justifiable pedagogical optimism of cultural revolutionaries is not just the sunny side of the equally justified stoicism of principled pedagogical "realism". The two perspectives grow from different world views that generate different pedagogical strategies, different research paradigms, perhaps even different epistemologies, at least for a while. Better each go their own way. Let the Dionysian partisan activists specialize in finding leverages of change-e.g. how collaborative learning environments empower learners, what scaffolding helps learners over what seemed before to be 'innate' constraints. But also let the Apollonian realists explore 'natural' constraints and seek out the regularities they impose on development, wherever found in whatever culture. (Bruner 1996, online)
}

If one looks for learning in the individual's construction the origins of meaning being in the social-cultural-historical cannot be taken into the account. Conversely, if one looks for learning in social-cultural-historical processes, through analyses in the ZPD, or in Activity Theory, studies of individual students' construction of knowledge won't suffice.

\subsection{An Example of Coherence}

As will be clear from the earlier sections of this chapter I find the work of the sociologist of education Basil Bernstein extremely important and useful in my understanding of educational processes. I could say the same for Pierre Bourdieu, or Michael Apple, or a number of other sociologists of education, though through historical circumstances I have worked with Bernstein's sociological theories (e.g., Morgan et al. 2002; Lerman 2014b) and with Vygotsky's (e.g., Lerman 2001; Meira and Lerman 2009). I have to ask the question: is Bernstein's work coherent with Vygotsky's? 
We can answer this in the positive. What they have in common is that both were Marxist theorists, both worked with the following idea:

It is not the consciousness of men that determines their being but, on the contrary, their social being that determines their consciousness. (Marx 1859, pp. 328-329)

Taking this theoretical argument either sociologically or cognitively, the task of the researcher is to set out indicators of how one would identify the social being determining consciousness, and carry out suitable research to reveal whether the theory is borne out. I will show two examples of research designed to confirm or otherwise the theories of Bernstein and of Vygotsky elaborating, from their theoretical positions, this statement of Marx.

For Bernstein, language and meanings can be classified into context dependent and context independent, reflecting what he calls restricted and elaborated codes respectively. When children begin school they will have acquired one of these two codes depending on social class (a concept relevant in Britain still, though harder to identify in recent decades), the former associated with the working class, the latter with the middle class. Schooling is concerned with context independent meanings and so children entering school with that orientation to meaning will be immediately at an advantage. In this way, schooling reproduces social inequality. It should be made clear, though, that this is not a deficit model, merely a contingent outcome of a particular home life and education.

The study reported is of eight-year olds being interviewed over their classification of pictures of food items. The social class of each of the children was identified before the study (Holland 1981). The children were asked to group the foods in whichever way they wished. The two strategies were everyday ones, such as 'these I like, these I don't like' and by organisational criteria such as 'these are vegetables, these are fruit' and so on. She concluded as follows:

\footnotetext{
Our results showed that the children in our sample did differ in the way in which they contextualised the pictures of food items which were used - some emphasized their own experience with such items, and others stressed general properties of the items. These differences emerged most clearly in their own first and last groupings, when the basic orientation informed their organization of the entire set of food items, and were clearly related to social class position. Those children who used chiefly a context independent orientation to meaning were middle class, and those who focussed their contextualizations in terms of their practical experience of food and were thus oriented towards context dependent meaning, were working class. (p. 16)
}

Vygotsky, taking the same Marxist notion, argued that, in the opportunity arising from the Russian revolution in which education was a vital element of the new social organisation for the freed peasants, it should be possible to observe changes in meanings of everyday objects for people, just as in the food pictures. In place of research requiring a longitudinal change to observe the development of higher thinking, as he called it, Vygotsky and his student and colleague Luria designed a study of members of collective farms, kolhoz, which included peasants who had not had any schooling, peasants who had become involved in organising the community, and children who were attending school. In that way they were approximating 
a longitudinal study of the process of intellectual development and change. The three groups were presented with three everyday objects, an axe, a hammer and a piece of wood. They, too, were asked to group the objects. In this case the everyday, context dependent response was that they all belong together since hammer and saw are useless without wood to work on, and the context independent response of a division into tools, the saw and hammer, and object to be worked on, the wood. The first two groups, the peasants involved in the community and those not involved, employed the context dependent meanings. The schooled children employed the context independent meaning. Vygotsky and Luria concluded as follows:

\footnotetext{
Our investigations, which were conducted under unique and non-replicable conditions involving a transition to collectivized forms of labour and cultural revolution, showed that, as the basic forms of activity change, as literacy is mastered, and a new stage of social and historical practice is reached, major shifts occur in human mental activity... A basic feature of the shifts we observed is that the role of direct graphic-functional experience was radically altered in the transition to collectivized labor and new forms of social relations and with the mastery of rudiments of theoretical knowledge. (Luria 1976, pp. 161-162)
}

In contrast to what I see as a confusion of constructivist and sociocultural theories which have many elements of fundamental difference and indeed contradictions, I have presented briefly how the two intellectual fields of sociology, specifically Bernstein's sociology of education, and psychology, specifically Vygotsky's can be seen to be coherent. I am not claiming that coherence can be achieved only when two theoretical accounts both draw from the same fundamental inspiration. I am arguing that researchers, in their doctoral studies or in other research, need to do the work necessary to show how theories articulate together, and that they do not carry hidden contradictions. It has been intentional, of course, that the example of contradictory theories and the example of coherent theories overlap. I have been interested in these ideas for more than 30 years.

\subsection{Concluding Remarks}

In this chapter I have discussed the role of theory or theories in research in mathematics education, as a sub-field of educational research. I have set particular features of research in mathematics education within the explanatory framework provided by Basil Bernstein: its face to practice and at the same time its face to theory; and its horizontal knowledge structure leading to multiple competing discourses existing and developing separately alongside each other. I have tried to do this in general terms but also not to hide my own orientation, that of coherence where the researcher draws from more than one theory.

As one of the gatekeepers I have referred to, those who select students for research grants, examine doctoral students, review articles for journals, interview for positions and promotions, or select research projects for funding, I do not demand or expect any particular theory or theories to be worked with. If the 
researcher has done her/his job well in working with theory or theories, whatever they be, I will be happy. I do expect a position to be taken in relation to working with theory or theories, with a rationale, as I have tried to do in this chapter.

These concluding remarks are not just a brief repeat of the themes in the chapter. In reading/examining a thesis I expect a researcher to reflect, at the end, on the theoretical position taken and its fruitfulness for the research. That reflection may mean proposing developments of the theory, or it may not. But that reflection, as mine here, is an important final step, not to be neglected.

\section{References}

Ball, D. L. (1993). With an eye on the mathematical horizon: Dilemmas of teaching elementary school mathematics. Elementary School Journal, 93, 373-397.

Bernstein, B. (1990). The structuring of pedagogic discourse: Class, codes and control (Vol. 4). London: Routledge.

Bernstein, B. (2000). Pedagogy, symbolic control and identity: Theory, research, critique. Maryland: Rowman \& Littlefield.

Bruner, J. (1996). Celebrating divergence: Piaget and Vygotsky. https://people.ucsc.edu/ $\sim$ gwells/Files/Courses_Folder/.../Bruner_Piaget-Vygotsky.pdf

Cohen, L., Manion, L., \& Morrison, K. (2018). Research methods in education (7th ed.). Abingdon, Oxon: Routledge

Davis, Z. (2001). Measure for measure: Evaluative judgement in school mathematics pedagogic texts. Pythagoras, 56, 2-11.

de Freitas, E. (2017). Biosocial becomings: Rethinking the biopolitics of mathematics education research. In A. Chronaki (Ed.), Proceedings of the Ninth International Mathematics Education and Society Conference. Greece, Volos: University of Thessaly Press.

Dowling, P., \& Brown, A. (2010). Doing research/reading research: Re-interrogating education. Abingdon, Oxon.: Routledge.

Ensor, P. (2001). From pre-service mathematics teacher education to beginning teaching: A study in recontextualising. Journal for Research in Mathematics Education, 32, 296-320.

Goldin, G.A. (2003). Developing complex understandings: On the relation of mathematics education research to mathematics. In R. Even, \& D. Loewenberg Ball (Eds.), Special Issue. Educational Studies in Mathematics, 54, (2-3), 171-202.

Hodkinson, P. (2004). Research as a form of work: Expertise, community and methodological objectivity. British Educational Research Journal, 30(1), 9-26.

Holland, J. (1981). Social class and changes in orientation to meaning. Sociology, 15(1), 1-18.

Karmiloff-Smith, A., \& Inhelder, B. (1974). If you want to get ahead, get a theory. Cognition 3(3), 195-212.

Kilpatrick, J. (1981). The reasonable ineffectiveness of research in mathematics education. For the Learning of Mathematics, 2(2), 22-29.

Kuhn, T. (1978). The structure of scientific revolutions. Chicago: Chicago University Press.

Lather, P. (2006). Paradigm proliferation as a good thing to think with: Teaching research in education as a wild profusion. International Journal of Qualitative Studies in Education, 19(1), $35-57$.

Lerman, S. (1996). Intersubjectivity in mathematics learning: A challenge to the radical constructivist paradigm? Journal for Research in Mathematics Education, 27(2), 133-150.

Lerman, S. (2000). The social turn in mathematics education research. In J. Boaler (Ed.), Perspectives on teaching and learning (pp. 19-44). Westport, CT: Ablex. 
Lerman, S. (2001). Accounting for accounts of learning mathematics: Reading the ZPD in videos and transcripts. In D. Clarke (Ed.), Perspectives on practice and meaning in mathematics and science classrooms (pp. 53-74). Dordrecht: Kluwer.

Lerman, S. (2013). Technology, mathematics and activity theory. The International Journal for Technology in Mathematics Education, 20(1), 39-42.

Lerman, S. (Ed.). (2014a). Encyclopedia of mathematics education. Dordrecht: Springer.

Lerman, S. (2014b). Mapping the effects of policy on mathematics teacher education. Educational Studies in Mathematics, 87(2), 187-201.

Luria, A. R. (1976). Cognitive development: Its social and cultural foundations. Cambridge MA: Harvard University Press.

Marx, K. (1859). A preface to contribution to the critique of political economy. Marx and Engels selected works (pp. 361-365). London: Lawrence and Wishart.

Meira, L., \& Lerman, S. (2009). Zones of proximal development as fields for communication and dialogue. In C. Lightfoot, \& M. C. D. P. Lyra (Eds.), Challenges and strategies for studying human development in cultural contexts (pp. 199-219). Rome: Firera Publishing.

Morgan, C., Tsatsaroni, A., \& Lerman, S. (2002). Mathematics teachers' positions and practices in discourses of assessment. British Journal of Sociology of Education, 23(3), 443-459.

Prediger, S., Bikner-Ahsbahs, A., \& Arzarello, F. (2008). How can networking strategies for connecting theoretical approaches help to develop theories in mathematics education? First Reflections. ZDM, 40(2), 165-178.

Silver, E. A., \& Herbst, P. (2007). Theory in mathematics education scholarship. In F. K. Lester (Ed.), Second handbook of research on mathematics teaching and learning (pp. 39-67). Charlotte, NC: Information Age Publishing and Reston, VA: National Council of Teachers of Mathematics.

Sriraman, B., \& English, L. (2005). Theories of mathematics education: A global survey of theoretical frameworks/trends in mathematics education research. Zentralblatt für Didaktik der Mathematik, 37(6), 450-456.

Sriraman, B., \& English, L. (2010). Surveying theories and philosophies of mathematics education. In B. Sriraman, \& L. English (Eds.), Theories of mathematics education (pp. 7-32). Berlin: Springer.

Open Access This chapter is licensed under the terms of the Creative Commons Attribution 4.0 International License (http://creativecommons.org/licenses/by/4.0/), which permits use, sharing, adaptation, distribution and reproduction in any medium or format, as long as you give appropriate credit to the original author(s) and the source, provide a link to the Creative Commons license and indicate if changes were made.

The images or other third party material in this chapter are included in the chapter's Creative Commons license, unless indicated otherwise in a credit line to the material. If material is not included in the chapter's Creative Commons license and your intended use is not permitted by statutory regulation or exceeds the permitted use, you will need to obtain permission directly from the copyright holder. 